\begin{tabular}{l}
\multicolumn{1}{c}{ AUSTRALIAN JOURNAL OF BASIC AND } \\
APPLIED SCIENCES \\
$\begin{array}{l}\text { ISSN:1991-8178 } \\
\text { EISSN: } 2309-8414 \\
\text { DOI: } 10.22587 / \text { ajbas.2017.11.13.13 } \\
\text { Journal home page: www.ajbasweb.com }\end{array}$
\end{tabular}

\title{
Properties of Mortar with Red Gypsum as Cement Replacement Material by Using Industrial Approach Method
}

${ }^{1}$ Mohd Amirul Hakim Sidek, ${ }^{1}$ Rosli M. Yunus, Fadzil Mat Yahaya, ${ }^{1}$ Muhammad Faisal Baderolhissam, ${ }^{1}$ Mohamad Al-Nizar Khan Ahmad Khan

${ }^{1}$ Universiti Malaysia Pahang, Faculty of Chemical Engineering \& Natural Resources, 26300 Gambang, Pahang, Malaysia.

${ }^{2}$ Universiti Malaysia Pahang, Faculty of Civil Engineering \& Earth Resources, 26300 Gambang, Pahang, Malaysia.

Address For Correspondence:

Mohd Amirul Hakim Sidek, Universiti Malaysia Pahang, Faculty of Chemical \& Natural Resources Engineering, Gambang Campus, 26300, Kuantan, Pahang, Malaysia.

Phone: +60179242977; E-mail: amirul.hsk@gmail.com

\section{A R T I CLE INFO}

\section{Article history:}

Received 19 August 2017

Accepted 1 November 2017

Available online 11 November 2017

Keywords:

Bricks; $\quad$ Mortars; Fine

Aggregate; Sand Replacement;

\begin{abstract}
A B S T R A C T
Background: Utilization of Red Gypsum, a common industrial waste, in the manufacturing of cement brick can mitigate the deterioration of environment as it can preserveland piling of RG waste. X-Ray fluorescence analyzer was utilized to determine the chemical composition of Red Gypsum (RG) while sieving method was used to determine its particle size distribution. From the analyses, it can be concluded that RG properties suit the purpose of replacing cement for production of low strength mortar. A range of physical and mechanical tests were conducted on various percentage of cement replacement in RG cement bricks. This paper focused on verifying formulation and water ratio to meet the compressive strength tests needed as required for low strength mortar and the effects on the quality. From the results of this study, it can be concluded that RG cement bricks complied with the Malaysian Standard 76:1972 (Specifications for bricks and blocks of brick earth, clay or shale) for non-load bearing walls. The results also indicated that a maximum range of $60-70 \%$ replacement can be done without compromising the minimum quality of the produced bricks.
\end{abstract}

\section{INTRODUCTION}

In Malaysia, construction industry plays a vital role in the economic growth through the development of commercial buildings and the infrastructure of the country. In 2015, the Construction Industry Development Board (CIDB) of Malaysia stated that the 'construction industry' stood as the third-biggest sector in term of productivity,only next to manufacturing and agriculture sector. Besides, this industry has been linked to the expansion of other industries such as manufacturing supplies and services. In parallel to the rapid growth in the construction industry, it is also associated with the deterioration of environment and the increased emission ofcarbon dioxide $\left(\mathrm{CO}_{2}\right)$.

Cement manufacturing has been known as one of the major contributors to the emission of $\mathrm{CO}_{2}$ due to calcinations of raw materials and maintaining high temperature in kiln using burning fuels. Ali et al. (2015) stated that the production of cement in the construction industry subsector required $12 \%$ of the total energy consumedin Malaysia.The main source of this energy is the combustion of fuels such as coal, petroleum coke, natural gas, diesel and fuel oil. Hence, reducing the usage of cement in building construction will directly reduce the demand of cement in the market. This will lead to drastic reduction in the release of carbon dioxide to the environment.

Various investigations to find the suitable alternatives so as to decrease the atmospheric $\mathrm{CO}_{2}$ concentration, besides reducing the cost of the construction material, has started years ago.But the demand and the usage of

Open Access Journal

Published BY AENSI Publication

(C) 2017 AENSI Publisher All rights reserved

This work is licensed under the Creative Commons Attribution International License (CC BY). http://creativecommons.org/licenses/by/4.0/

To Cite This Article: Mohd Amirul Hakim Sidek, Rosli M. Yunus, Fadzil Mat Yahaya, Muhammad Faisal Baderolhissam, Mohamad AlNizar Khan Ahmad Khan., Properties of Mortar with Red Gypsum as Cement Replacement Material by Using Industrial Approach Method. Aust. J. Basic \& Appl. Sci., 11(13): 115-121, 2017 
alternative materials to decrease the usage of cement is still limited in Malaysian construction industry. Nowadays, the conventional cement brick is widely used. The raw materialsin conventional cement brick are cement and sand. However, there are several alternative materials such as waste materials have been testedby researchers to replace cement in mortar and concrete. Fly ash, bottom ash and Ground Granulated Blast-furnace Slag (GGBS) are some of the common waste materials used to replace cement in concrete and mortar. These materials exhibit cement-like characteristicsand are classified as pozzolan materials.

Pozzolan materials such as fly ash, bottom ash and Ground Granulated Blast-furnace Slag can be used to replace cement in conventional cement bricks. Based on a research conductedby Islam \& Islam (2014), it was found that the cement can be replaced up to $40 \%$ by fly ash whereas the compressive strength achieved is slightly higher when compared to the conventional cement brick. Further, the cost incurred in manufacturing conventional cement bricks could also be reducedif the cement is replaced with fly ash. However, bricks containing pozzolan materials such as fly ash need to be cured properly as it exhibits low early strength due to slower hydration at early age. This problem prevents fly ash to be used as a replacement for cement in industrial scale (due to longer curing period and handling of the bricks).

Red Gypsum (RG) is another potential waste material that can replace cement in cement brick production. In Malaysia, more than1,000,000 tonnes ofRed Gypsum waste is generated every year. Most of this waste is dumped in secured landfills without being utilized. With the current trend of production, eventually there will be a new application from Red Gypsum waste generator to build an additional landfill to cater the growing demands of its RG waste handling. Utilizing RG in cement brick manufacturing can reduce the piling of RG at landfills significantly. Furthermore, RG has been suggested as a cement replacement in brick due to its chemical properties, cost and availability of the material.

Non-load bearing brick is the most appropriate construction material to be suggested, since the strength of this type of brick only requires $5 \mathrm{MPa}$ to meet the construction standards. Weak strength allows replacement of cement to be made in bulk. Usage of RG in bulk can reduce this waste material at landfills significantly and at the same time, it also reduces the dependency on cement for brick manufacturing.

The objective of this study is to examine the suitability of utilizingRed Gypsum in cement brick manufacturing, by varying the percentage of RG in the formulation and analyse its impact on the quality and strength of the produced bricks, using industrial scale manufacturing facility.

\section{Experimental:}

Materials:

Ordinary Portland cement (OPC) from Lafarge Malaysia Berhad was used in this study. This material was manufactured in meeting the requirement of Malaysian Standard MS 522: Part 1: 1989 Specification for Ordinary Portland Cement. This cement is the most common material used in manufacturing cement brick. In this study, fresh red gypsum (RG) samples were collected from tioxide industry in Kemaman, Terengganu. The RG samples were sun-dried to assure a constant moisture content. River sand from nearby quarry was used in this study with nominal size of $4.75 \mathrm{~mm}$. The chemical composition of RG is tabulated in Table 1 .

Table 1: Chemical composition of red gypsum

Table 1: Chemical composition of red gypsum
\begin{tabular}{|l|l|l|l|l|l|l|l|l|l|l|l|}
\hline & $\mathrm{CaO}$ & $\mathrm{SO}_{3}$ & $\mathrm{Fe}_{2} \mathrm{O}_{3}$ & $\mathrm{MnO}$ & $\mathrm{TiO}_{2}$ & $\mathrm{~V}_{2} \mathrm{O}_{5}$ & $\mathrm{Cr}_{2} \mathrm{O}_{3}$ & $\mathrm{CuO}$ & $\mathrm{ZnO}$ & $\mathrm{Eu}_{2} \mathrm{O}_{3}$ & $\begin{array}{l}\text { Loss } \\
\text { Ignition }\end{array}$ \\
\hline Constituent & 32.2 & 31.6 & 28.99 & 0.41 & 5.64 & 0.22 & 0.032 & 0.063 & 0.24 & 0.26 & 0.345 \\
\hline
\end{tabular}

\section{Mixture Proportions:}

From the industrial manufacturing point of view, the mix proportions of RG bricks were designed in meeting the requirement of non-load bearing wall as stated in Malaysian Standard MS 72: 1976 Specification of Cement Bricks. Five series of RG-cement mixtures and one reference control mixture $\left(\mathrm{M}_{0}\right)$ were prepared. The proportion of each mix composition is summarized in Table 2.

Table 2: Mix Proportions of RG-cement

\begin{tabular}{|c|c|c|c|c|}
\hline Mix No & $\mathrm{RG}(\%)$ & Cement (\%) & Sand $(\%)$ & Replacement Percentage (\%) \\
\hline M0 & 0.00 & 25.00 & 75.00 & 0 \\
\hline M1 & 5.00 & 20.00 & 75.00 & 20 \\
\hline M2 & 10.00 & 15.00 & 75.00 & 40 \\
\hline M3 & 15.00 & 10.00 & 75.00 & 60 \\
\hline M4 & 20.00 & 5.00 & 75.00 & 80 \\
\hline M5 & 25.00 & 0.00 & 75.00 & 100 \\
\hline
\end{tabular}

In order to determine the most suitable amount of RG that can be used for manufacturing of conventional cement brick with RG replacement, twenty (20) pieces of conventional cement brick ages 28 days has been taken from brick plant nearby Gambang, Kuantan for compressive strength test. 


\section{Brick Pressing Machine:}

In this study, the RG bricks were manufactured using a semi-auto brick pressing machine. This machine consists of a mixer, conveyor, hopper and hydraulic press as shown in Figure 1. The pressure of the hydraulic press was set at 20MPa.

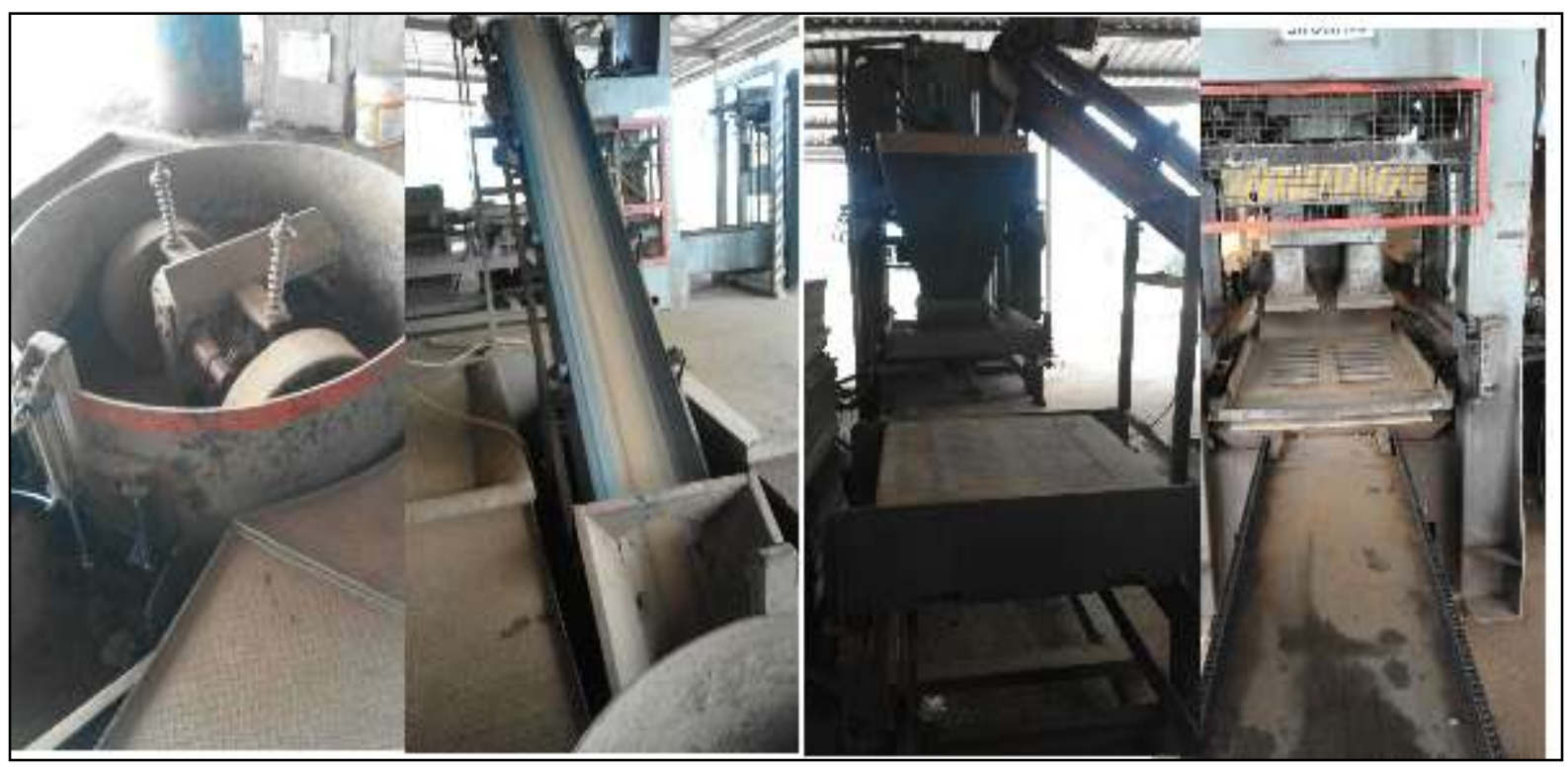

Fig. 1: Brick Pressing Machine

\section{Experimental Methods:}

This experiment was conducted by using industrial brick pressing machine which produced solid brick with dimension of $112.5 \times 90 \times 65 \mathrm{~mm}$. Cement, water and RG were mixed in the mixer for 1 min before the addition of fine aggregates. The total mixing time is about 3 minutes in acquiring a good adherence among the water, cement, RG and sand. The mix was then pressed under the pressure of $3000 \mathrm{kN}$ using hydraulic press machine. Thereafter, the manufactured bricks were cured naturally under air-dried. 10 samples from each mixture were taken during 7 and 28 days of curing for compressive strength test. Next, the best quality of mix with different water/cement ratio $(0.30,0.35,0.40,0.45,0.50)$ was determined by correlating the compressive strength results with average weight, thickness and condition of the pressed bricks.

\section{RESULTS AND DISCUSSION}

\section{Compressive strength of bricks with different replacement percentage:}

In Figure 2, the compressive strength of bricksproduced with different replacement percentage of cement by RG is shown. For comparison, the average compressive strength of Conventional Cement Brick (CCB) tested was $10.9 \mathrm{MPa}$.

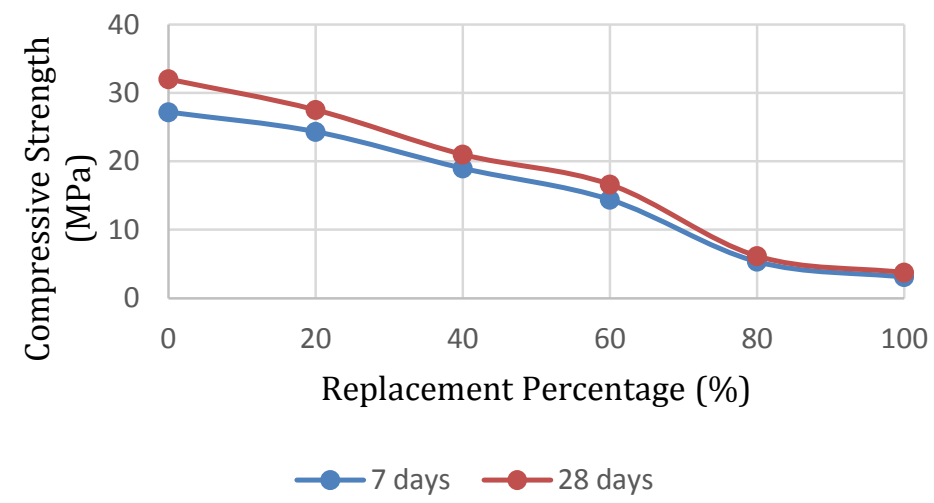

Fig. 2: Compressive strength of RG bricks with different replacement percentage 
From the figure, it can be inferred that the compressive strength of mortar decreased progressively with increasing percentage of RG. On the other hand, in general, the results indicated that there is an improvement in compressive strength with duration of curing. The improvement was highlypronounced especially at low replacement percentage. When approaching $80 \%$ cement replacement onwards, the difference in compressive strength, as a result of differences in curing time got diminished. The compressive strength decreased from 32 $\mathrm{MPa}$ at $0 \%$ replacement to $4 \mathrm{MPa}$ at $100 \%$ replacement. At $80 \%$ cement replacement, the compressive strength was recorded at $6.1 \mathrm{MPa}$ which exceeded the threshold limit (5 MPa) set by the Malaysian Construction Standard i.e.,MS 72: 1976.

Curing of cement bricks is a slow process. The curing of brick is very much related to the reactionprocess (hydration)that occur at the cement sites within the structure of the brick. Mainly, the reaction occur in two stages; first order linear reaction and the second order reaction. The first stage of reaction, on an average, takes place in seven days. This relatively fast reaction increased the compressive strength of the brick significantly. After seven days, the cementing reaction enters the second order reaction, which is slow, but continuous in nature. The ultimate strength of the brick is achieved on the $28^{\text {th }}$ day of curing, upon which the strength of the cement brick is relatively constant.

The amount of cement particles in the brick influences the duration to complete the reaction process. More cement particles usually increases the duration of curing of bricks in order to achieve the ultimate strength. During the hydration reaction, dicalcium silicate and tricalcium silicate (cement components) react with water to form silica gel and calcium hydroxide $\left(\mathrm{Ca}(\mathrm{OH})_{2}\right)$. According to Neville (1995), the hydrated silica gel bind the unhydrated component in the brick together while being coated by calcium hydroxide. Early stage of hydration process shows a first order linear reaction since there is a continuous water phase within the brick structure. Eventually, the continuous water phase diminishes and left with dispersed water droplets. The hydration reaction stiffened the brick, and at the same time created amore difficultsituation for the unhydrated cement particle to absorb the dispersed water droplets within the brick. Nevertheless, as long as there are still unhydrated cement particles and water droplets in the brick, hydration reaction will continue to take place, but at a slower pace, reflecting the second order reaction. The results presented in Figure 2 indicates the significant differences found between the compressive strengths of two curing times (i.e., 7 days and 28 days), especially at low percentage of cement replacement.

The replacement of cement with RG decreased the compressive strength of the brick.Theoretically, pozzolanic material reacts with calcium hydroxide which is produced due to hydration of cement, and gets hardened. Reduced amount of cement in the mixture proportionately lowered the amount of dicalcium and tricalcium silicates, which are responsible for the hydration process in turn there is a decreased amount of calcium hydroxide production. With lower amount of calcium silicates, the production of silica gel, which is the binding agent responsible in strengthening the brick, is reduced. Simultaneously, there is a competition for water droplets within the brick between cement particles, which require water for its hydration process, and RG which has strong tendency to absorb and retain water droplets. The competition retarded the hydration process of cement component due to lack of water which resulted in lower compressive strength. In addition, the decreased compressive strength may also be linked to the lack of pozzolanic activity of RG (secondary reaction that generates silica gel which helped increase the strength of the product). This finding is consistent with the conclusion fromGazquez et al (2013) in which it was inferred that the replacement of cement by RG above $20 \%$ may reducethe compressive strength of mortar produced. Nevertheless, this study showed that replacement of cement up to $80 \%$ is still acceptable, since it produced bricks with strength above the minimum acceptable compressive strength (i.e., $5 \mathrm{MPa}$ ) set by the Malaysian Construction Standard, MS 72: 1976 for non-load bearing brick. Comparing the compressive strengths of the commercial cement brick, $10.9 \mathrm{MPa}$, the value relates to the percentage replacement in the range of $60 \%$ to $80 \%$ (Figure 2). Hence, a study was conducted, to zoom in, the manufacturing of low strength mortar in the range of 60 to $80 \%$ cement replacement, in order to identify the percentage of cement replacement, which will produce bricks with average compressive strength closest to the conventional cement bricks of $10.9 \mathrm{MPa}$.

Table 3: Mix Proportions of predicted low strength mortar

\begin{tabular}{|l|l|l|l|l|}
\hline Mix No. & RG $(\%)$ & Cement (\%) & Sand (\%) & Percentage Replacement (\%) \\
\hline M3a & 16.50 & 8.50 & 75.00 & 66 \\
\hline M3b & 17.25 & 7.75 & 75.00 & 69 \\
\hline M3c & 18.00 & 7.00 & 75.00 & 72 \\
\hline M3d & 18.75 & 6.25 & 75.00 & 75 \\
\hline M3e & 19.50 & 5.50 & 75.00 & 78 \\
\hline
\end{tabular}

Table 3 shows the mix proportions of $66 \%$ to $78 \%$ replacement of cement by RG, while figure 3 shows the close-up results of compressive strength between $66 \%$ to $78 \%$ replacement of cement by RG. 


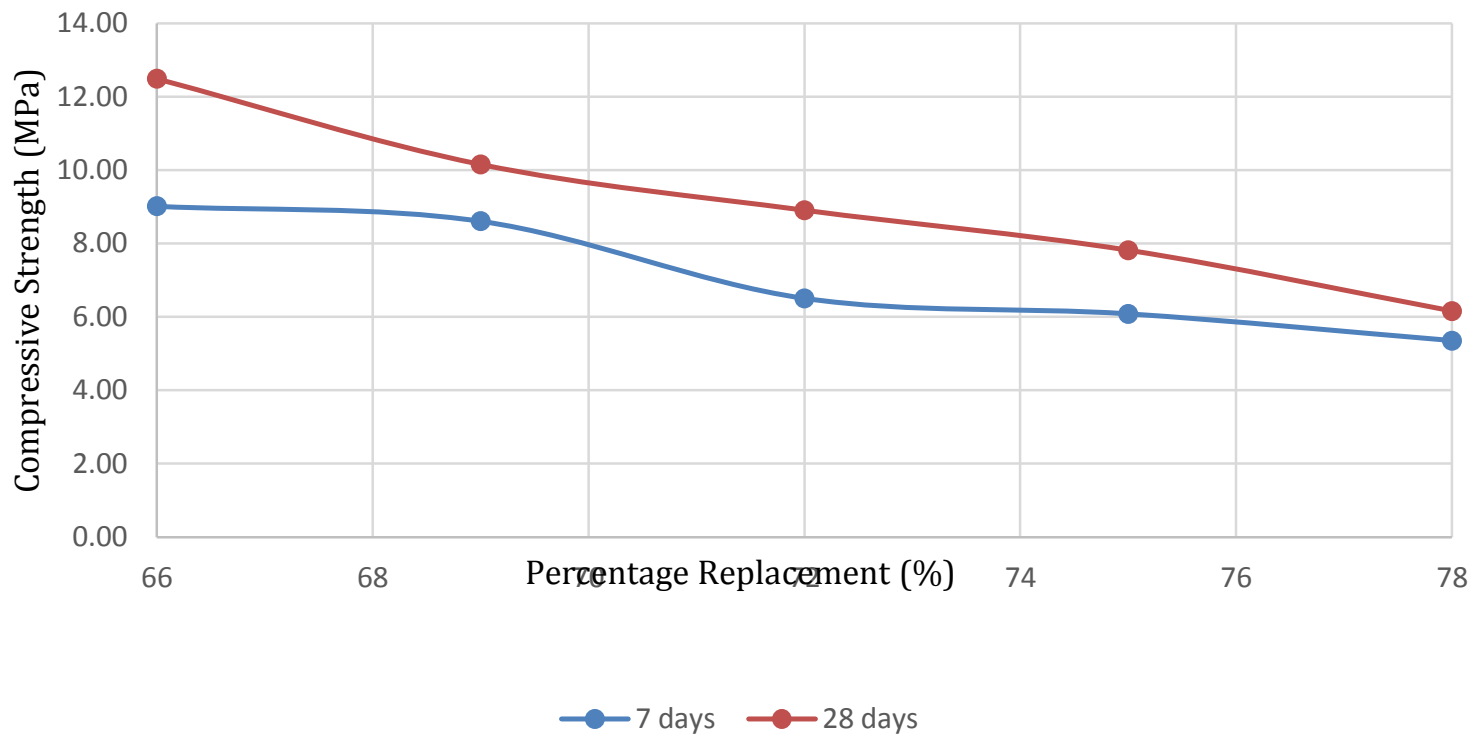

Fig. 3: Compressive strength of predicted low strength mortar

In accordance with the earlier results, the figure 3showsthat there is a decrease in compressive strength along with the increasein percentage replacement of RG. The effect of curing time until $28^{\text {th }}$ days showed almost the same trend even though there is less improvement of strength at 69\% replacement (M3b) compared to $72 \%$ replacement (M3c). The compressive strength on $28^{\text {th }}$ day decrease from $12.49 \mathrm{MPa}$ at $66 \%$ replacement to 6.16 $\mathrm{MPa}$ at $78 \%$ replacement. At 66\% replacement (M3a) and 69\% replacement (M3b), the samples tested achieved compressive strength of $12.49 \mathrm{MPa}$ and $10.15 \mathrm{MPa}$, respectively,indicating that cement replacement in between $66 \%$ and $69 \%$ would ideally produce bricks with compressive strength similar to the conventional cement brick $(10.9 \mathrm{MPa})$.

Apart from cement, hydration reaction in cement brick also depends on the availability of water/moisture within the brick structure. RG has a strong tendency to absorb water. Thus, adding RG in the mixture creates competition between cement and RG to absorb water droplets. This phenomenon resulted in an increase of water/cement $(w / c)$ ratio to give maximum strength of the produced bricks. In order to examine the effect of w/c ratio, an experiment was conducted to vary the w/c ratio for mix composition of $66 \%$ replacement (M3a) since the mixture produces bricks with compressive strength slightly above the conventional cement bricks. Figure 4 shows the compressive strength of different w/c ratio of M3a.

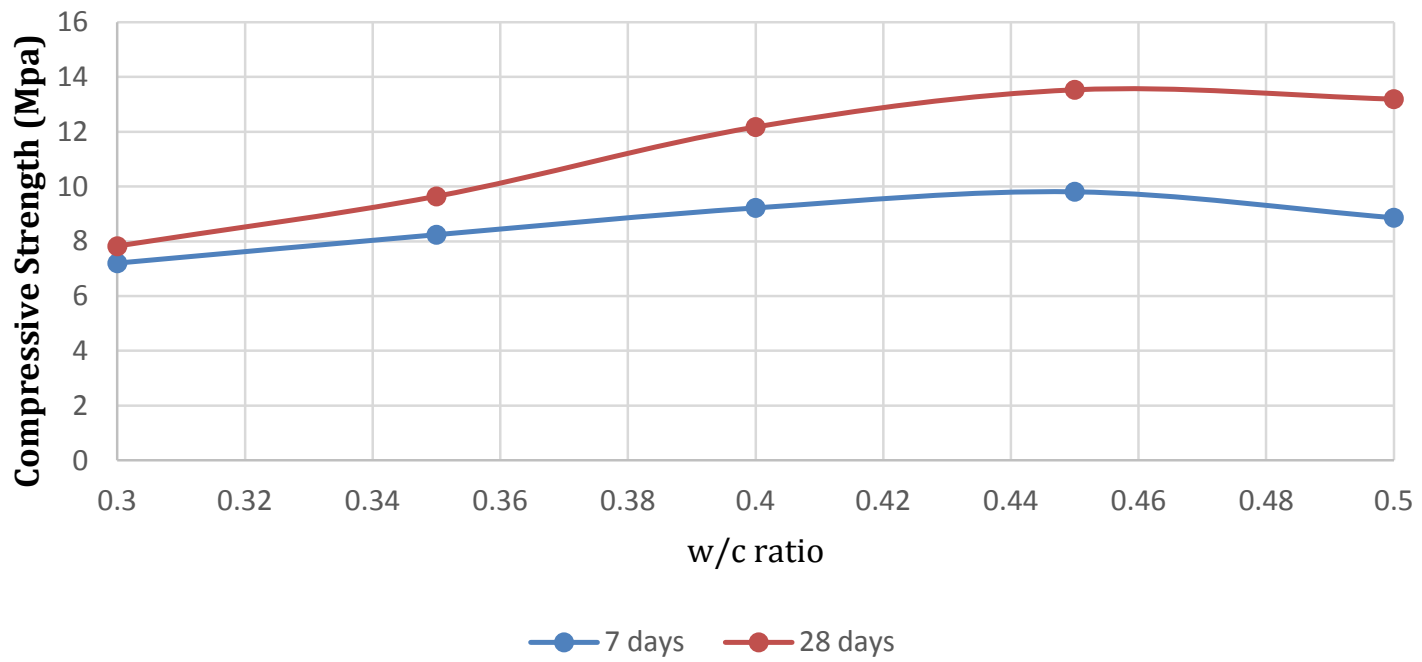

Fig. 4: Compressive Strength of different w/c ratio of M3a

Based on Figure 4, it can be inferred that the compressive strength increases with increasing w/c ratio until the curve reaches its peak at $0.45 \mathrm{w} / \mathrm{c}$. At this w/c ratio, the amount of water needed for a complete reaction is sufficient.When this ration is exceeding, there is a decreasing trend of compressive strength observed.Hence, 
this indicates that adequate amount of water is important in achieving the optimum compressive strength for a particular mix composition. Due to lack of water, shortcoming of complete hydration reaction has occurred. On the other hand, when the optimum amount of water exceeded, it also affected the compressive strengthnegatively.

The figure 4 also indicates the importance of curing time.At optimum w/c ratio (0.45), the compressive strength of the brick with curing time of 28 days was recorded at $13 \mathrm{MPa}$, while for the 7 days curing time, it was recorded at $10 \mathrm{MPa}$ i.e., a difference of $30 \%$. In comparison, at $0.3 \mathrm{w} / \mathrm{c}$ ratio, the difference in compressive strengths between the two curing times is less than $10 \%$. Curing time of the brickbring significant changes on the compressive strength due to the availability of enough time for the cement particles to complete the reaction. However, at low w/c ratio, the hydration reaction was limited and the reaction retarded as there was insufficient water to complete the reaction. The differences in compressive strengthsgot obviously increased with increasing w/c ratio. The results showed that the $\mathrm{RG}$ bricks need more water in order to achieve its ultimate strength due to the competition for the water droplets between cement particles and RG itself. Increasing w/c ratio ensured that the unhydrated cement component complete the hydration process and strengthen the bricks.

The decreased compressive strength shown with $0.5 \mathrm{w} / \mathrm{c}$ ratio was due to the stickiness nature of the mix composition at this w/c ratio which affected the quality of brick produced when pressing. Figure 5 and Figure 6 show the condition of bricks produced after pressing, with different w/c ratio.

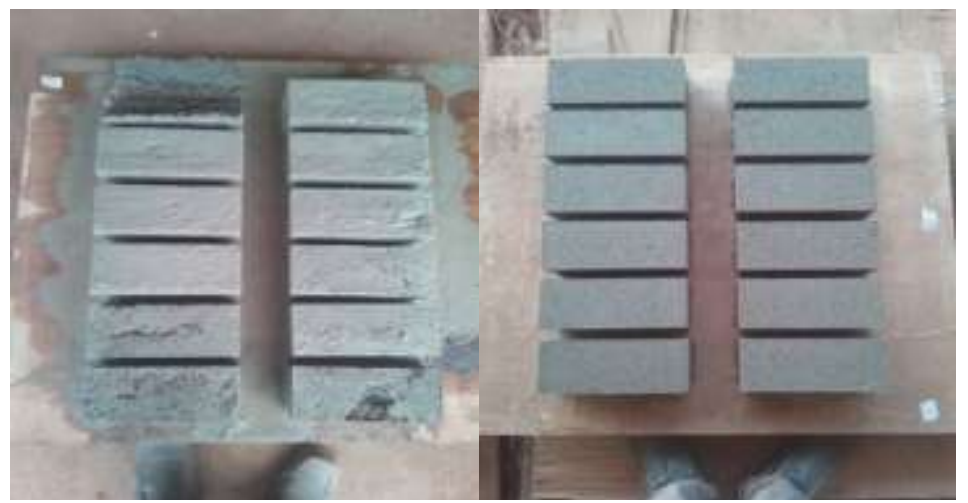

Fig. 5: $0.5 \mathrm{w} / \mathrm{cFigure} 6: 0.45 \mathrm{w} / \mathrm{c}$

\section{Quality of brick:}

The ratio of water-to-cement used in mixing the mortar influences the quality of bricks produced. The casting of M3a using different w/c ratio gave different value of weight and thickness. All mixes meet the requirement for compressive strength stated in MS 76:1972 for non-load bearing wall. Table 4 shows the average weight and thickness for all mixes. M3a5 with $0.5 \mathrm{w} / \mathrm{c}$ ratio showed the highest values of weight and thickness. The increasing trend of weight and thickness of bricks produced, in the event of increasing the w/c ratio is very much related to the nature of mix mortar during pressing. During pressing, mix mortar was pressed into the brick mould. The pressure exerted onto the mix compressed the mix into shape and spilled the excess material out of the mould. The resulted thickness and weight of the brick reflects the equivalent pressure opposing the $20 \mathrm{MPa}$ pressure applied during pressing.

Table 4: Average weight and thickness of M3a

\begin{tabular}{|l|l|l|l|}
\hline Mix No. & Water/cement ratio & Average Weight $(\mathrm{kg})$ & Average Thickness (mm) \\
\hline M3a1 & 0.30 & 3.15 & 63 \\
\hline M3a2 & 0.35 & 3.21 & 63 \\
\hline M3a3 & 0.40 & 3.31 & 65 \\
\hline M3a4 & 0.45 & 3.34 & 65 \\
\hline M3a5 & 0.50 & 3.58 & 70 \\
\hline
\end{tabular}

\section{Conclusion:}

Content of cement is the primary requisite that determine the strength of the brick. RG utilization as cement replacement reduces the compressive strength of the mortar. The presence of RG in cement brick increases the required $\mathrm{w} / \mathrm{c}$ ratio.Optimum w/c ratio increases the compressive strength of the brick to its optimum value. In general, increasing the w/c ratio, will increase the compressive strength, its weight and thickness of the brick. Exceeding the optimum w/c ratio affects the quality of the produced brick for it creates difficulty in casting the brick. Sufficient curing time and w/c ratio are two important factors that one needs to consider in order to produce good quality RG bricks. The optimum condition to achieve quality of RG bricks at par with the conventional cement brick is when using $66 \%$ cement replacement, with $0.45 \mathrm{w} / \mathrm{c}$ ratio and 28days curing time, producing RG bricks with compressive strength of $13 \mathrm{MPa}$. 


\section{REFERENCES}

Ali, M.B., R. Saidur and M.S. Hossain, 2011. A review on emission analysis in cement industries. Renewable and Sustainable Energy Reviews, pp: 2252-2261.

Azdarpour, A., M. Asadullah, R. Junin, M. Manan, H. Hamidi and E. Mohammadian, 2014. Direct Carbonation of red gypsum to produce solid carbonates. Fuel Processing Technology, pp: 429-434.

Fauziah, I., S. Zauyah and T. Jamal, 1996. Characterization and land application of red gypsum: a waste product from titanium dioxide industry. The Science of the Total Environment, pp: 243-251.

Gazquez, M.J., J.P. Bolivar, F. Vaca, R. Garcia-Tenorio and A. Caparros, 2013. Evaluation of the use of TiO2 industry red gypsum waste in cement production. Cement \& Concrete Composites, pp: 76-81.

Islam, M.M. and M.S. Islam, 2010. Strength Behaviour of Mortar Using Fly Ash as Partial Replacement of Cement. Concrete Research Letters.

Karami, S., 2008. Using By-product Industrial Materials to Replace All Cement inConstruction Products. Coventry University.

Hughes, P.N., 2006. The Use of synthetic Red Gypsum as a construction material. University of Newcastle

Rahmani, O., R. Junin, M. Tyrer and R. Mohsin, 2014. Mineral Carbonation of Red Gypsum for CO2 Sequestration. Energy \& Fuel, pp: 5953-5958. 